Rev. Hist., N²8, vol. 1, Enero-Junio 2021: 395-422

ISSN 0717-8832

https://doi.org/10.29393/RH28-15HTDO10015

\title{
El historiador del tiempo presente como un sujeto "afectado por el pasado". Escritura de la historia y conciencia histórica*
}

\author{
The present time historian as a subject "affected by the past". History writing and \\ historical consciousness
}

Daniel Ovalle Pastén**

\section{RESUMEN}

El artículo plantea desde la teoría de la historia comprender la denominada Historia del Tiempo Presente (HTP), más allá de sus características disciplinares, como un fenómeno intelectual articulado desde el problema de la historicidad contemporánea. Para esto, sumándonos a las tesis que invitan a pensar su emergencia y desarrollo dentro de un régimen de historicidad presentista desde finales del siglo pasado hasta la actualidad, se propone entender al historiador e historiadora del tiempo presente como un sujeto "afectado por el pasado", valiéndonos de la propuesta conceptual de Paul Ricoeur acerca de la conciencia histórica. Desde esta óptica, que establece un análisis desde un sujeto cognoscente en relación al régimen de historicidad, se presenta una articulación que evalúa qué tipos de relaciones con el pasado y el futuro establece este tipo de escritura de la historia. Como corolario, la investigación establece que la HTP es generadora de un tipo de conciencia histórica particular que rompe con las lógicas del presentismo.

Palabras Claves: historia del tiempo presente, relaciones con el pasado, afectado por el pasado.

\section{ABSTRACT}

The article proposes, from the theory of history, to understand the so-called History of Present Time, beyond its disciplinary characteristics, as an intellectual phenomenon articulated from the problem of contemporary historicity. For this, adding to the thesis that invites to think about its emergence and development within a regime of presentism historicity from the end of the last century to the present, it is proposed to understand the historian of the present time as a subject "affected by the past", using Paul Ricoeur's conceptual proposal about historical consciousness. From this perspective, it establishes an analysis from a cognitive subject in relation to the historicity regime, an articulation is presented that evaluates what types of relations with the past and the future establish this type of history writing. As a

\footnotetext{
* Agradezco las recomendaciones y comentarios de los evaluadores de este artículo.

** Doctor en Historia. Académico en la Universidad Andrés Bello. Facultad de Educación y Ciencias Sociales. Departamento de Humanidades, Viña del Mar, Chile. ORCID: https://orcid.org/0000-0002-8220-7683. Correo electrónico: ovalle.daniel@gmail.com.
} 
corollary, the research establishes that HTP is a generator of a particular type of historical consciousness that breaks with the logic of presentism.

Keywords: History of present time, relations with the past, affected by the past.

Recibido: septiembre 2020

Aceptado: enero 2021

"Lo que no deja lugar a dudas, es la transformación de nuestras experiencias del tiempo durante los últimos treinta o cuarenta años. Su signo anunciador es el retroceso del futuro (...) el del régimen moderno de historicidad, que fue el carbón de la locomotora de la Historia"1

\section{Introducción}

Ya no es sorpresa en el campo historiográfico la investigación de fenómenos contemporáneos al historiador o historiadora que los "observa", donde el registro oral y la interpretación de memorias -muchas de ellas en pugna-, en conjunto con otro tipo de registros, caracterizan un campo del conocimiento histórico cada vez más importante. La llamada Historia del Tiempo Presente (en adelante HTP) es una realidad intelectual consolidada en el mundo académico, por tanto, objeto de estudio para los dedicados al análisis historiográfico y la teoría de la historia ${ }^{2}$. Ambos enfoques, aunque problemas de investigación distintos, se presentan hoy necesariamente complementarios. Desde la teoría de la historia, este trabajo se posiciona a partir del estudio de la conciencia histórica -desde el fenómeno de la historicidad-en relación a la escritura de la historia, en particular la HTP. En otras palabras, este trabajo se posiciona desde la sistematización de la autorreflexión disciplinar, trabajo reflexivo que obliga al teórico de la historia a problematizar: a) distintas ideas del mundo; b) teorías y métodos que sustenten la cientificidad de la disciplina que estudia el pasado; c) las formas de narración de esas representaciones y d) las funciones sociales del trabajo historiográfico ${ }^{3}$.

Lo que presento a continuación explora la relación entre HTP e historicidad desde la emergencia de un nuevo régimen de historicidad llamado "presentismo" ${ }^{4}$, marco mayor que

\footnotetext{
${ }^{1}$ Hartog, François. 2013. Croire en l'histoire, París, Flammarion, p. 289-290.

2 En otro artículo expuse qué es actualmente la teoría de la historia (lejos de las ya superadas filosofías de la historia teleológicas de fines del siglo XIX y parte del XX), así como sus principales tendencias: Ovalle, Daniel. 2019b. "Actualidad en teoría de la historia: una mirada desde las relaciones con el pasado", Autoctonía, Vol. 3 №1, pp. 1627.

${ }^{3}$ Rüsen, Jörn. 2014. Tiempo en ruptura, México, Universidad Autónoma Metropolitana Azcapotzalco, p. 96-97.

${ }^{4}$ Hartog, François. 2003. Régimes d'historcité. Présentisme et experience du témps, París, Seuil. María Inés Mudrovcic ya ha planteado la posible relación entre régimen de historicidad y régimen historiográfico (en particular
} 
permite comprender el desarrollo de este tipo de escritura de la historia bajo una mirada estructural del tiempo histórico anclada en el sujeto historiador del tiempo presente ${ }^{5}$. François Dosse nos conmina a tomar en serio el estudio de la historicidad en relación con toda escritura de la historia, explicando que :

"el historiador debe pensar, más que nunca, la historicidad misma de su trabajo y la historicidad de toda categorización de las realidades sociales del pasado (... lo que) conduce al historiador a una interrogación epistemológica e historiográfica más ambiciosa y más cargada de desafíos que antes" ${ }^{\prime \prime}$.

La intención de historizar el tiempo presente no es algo nuevo. La disciplina reconoce sus orígenes al menos desde Herodoto y Tucídides como los primeros trabajos en búsqueda por la comprensión de hechos pasados desapegados para su entendimiento del uso del pensamiento mitológico. Precisamente, estos primeros relatos acudieron a la oralidad y observación de acontecimientos en primera persona. Entonces - para evitar confusiones con historiadores de otros presentes- cuando digo analizar la HTP bajo el prisma del presentismo contemporáneo, propongo situarlo bajo el análisis de los tipos de relaciones con el pasado ${ }^{7}$ que establece el o la historiadora del tiempo presente con respecto a su objeto de estudio. Herman Paul, en diálogo con Marc Day y el mismo Rüsen, explicó que todo pensamiento histórico remite a lo menos a cinco tipos de relaciones con el pasado: epistémica, moral, política, estética y material ${ }^{8}$. Pero no solo con el pasado se relaciona todo historiador, también con el futuro, allí su relación con el problema de la conciencia histórica y el sentido. Y acá un punto no menor: la escritura de la historia -su operación metódica (y epistémica) - y el conocimiento histórico, no pueden ser considerados sinónimos de conciencia histórica, pues ella sobrepasa en mucho al trabajo disciplinar ${ }^{9}$. Es un fenómeno cultural.

En ese contexto, se plantea que el historiador e historiadora del tiempo presente es un sujeto afectado por el pasado que escruta, lo cual me permitirá desarrollar preliminarmente qué tipos de relaciones temporales establece su trabajo y así comprender este tipo de escritura

presentismo e HTP) en una publicación reciente. Este artículo pretende sumar a la propuesta, considerando que es parte de una discusión todavía en desarrollo, ver Mudrovcic, María Inés. 2013. "Regímenes de historicidad y regímenes historiográficos: del pasado histórico al pasado reciente" Historiografías № 5, 11-31.

${ }^{5}$ En la segunda parte de este trabajo se desarrolla con detalle la noción de régimen de historicidad. Solo decir, por ahora, que representa un maco mayor para la comprensión social del tiempo como herramienta heurística al modo weberiano de "tipos ideales".

${ }^{6}$ Dosse, François. 2012. El giro reflexivo de la historia. Recorridos epistemológicos y atención a las singularidades, Santiago, Ediciones Universidad Finis Terrae, p. 14.

7 Paul, Herman. 2015. Key Issues in Historical Theory, New York, Routledge.

8 Paul, Herman. 2015. "Relations to the past: a research agenda for historical theorists", Rethinking History Vol. 19, pp. 450-458.

9 Pihlainen, Kalle. 2014. “On historical consciousness and popular pasts”, Historia da Historiografia № 15, p. 12. 
de la historia desde la mirada de la experiencia. Su labor intelectual es una práctica con respecto al pasado investigado. La noción de estar "afectado por el pasado" la tomo de la filosofía del lenguaje de Paul Ricoeur, la cual me permitirá transitar desde el problema temporal estructural -régimen de historicidad presentista y conciencia histórica contemporánea ${ }^{10}$ - al ontológico (desde la impronta del sujeto) para así entender el desarrollado de la HTP desde los individuos que la representan dentro de un lugar social ${ }^{11}$. Esta mirada es precisamente la que permite seguir la huella planteada por De Certeau: lo social como condición de posibilidad de toda escritura de la historia que, para este caso, es el problema del tiempo. A partir de este enfoque se establece también una hipótesis secundaria: junto con entender este tipo de escritura de la historia como síntoma del presentismo, la HTP se presenta como un fenómeno intelectual que rompe con las lógicas del presentismo desde la generación de conciencia histórica, por lo que en la última parte de este trabajo relacionaré HTP con el problema del sentido histórico.

\section{El historiador del tiempo presente: un sujeto afectado por el pasado}

Problematizar la experiencia con respecto algo pasado es uno de los problemas que la teoría de la historia viene intentando develar en los últimos años ${ }^{12}$. Sin entrar en la discusión por las diferentes posturas intelectuales que hay al respecto ${ }^{13}$, esta investigación se sitúa desde los aportes que la hermenéutica filosófica nos entrega. Partiendo de la base que toda comprensión se lleva a cabo desde una determinada historicidad y que a la vez esta lleva inserto, según la hermenéutica, las tres categorías temporales ${ }^{14}$, esta investigación propone pensar al historiador/a del tiempo presente -y su operación historiográfica-como un sujeto en el mundo que se relaciona con el pasado que intenta comprender, siempre desde un presente, pero también a partir de una proyección de expectativas, toda vez que orienta sus investigaciones desde la articulación de sentido. Ocupar analíticamente la noción de "relación" es aceptar que lo que todo sujeto historiador hace al problematizar e investigar cualquier pasado es también una experiencia en el mundo. A la vez, con el uso de la expresión "afectado por el pasado" hacemos eco de la noción ontológica expresada por Ricoeur en el tercer tomo de Tiempo y

\footnotetext{
10 Hemos trabajado el problema de la conciencia histórica contemporánea desde un prisma teórico-estructural en Ovalle, Daniel. 2019c. "Pensar la conciencia histórica contemporánea. Historicidad y teoría de la historia" en Aravena, Pablo (Editor), Representación histórica y nueva experiencia del tiempo, Santiago, América en Movimiento, pp. 4763.

${ }^{11}$ De Certeau, Michel. 2010. La escritura de la historia, México, Universidad Iberoamericana, p. 81.

12 Ankersmit, Frank. 2005. Sublime Historical Experience, Stanford, Stanford University Press; Runia, Eelco. 2006. "Presence", History and Theory Vol. 45, 1-29; Kleinberg, Ethan. 2017. Haunting History. For a Deconstructive Approach to the Pas, Stanford, Stanford University Press.

13 Un interesante y recomendado texto que sí hace ese trabajo analítico en Escribano, Rodrigo. 2019. "Experience, symbol and communication: a transversal model for the study of historical thought", Historia Da Historiografia Vol. 12, № 29, pp. 153-178.

${ }^{14}$ Schaeffer, Jean-Marie. 2018. "Historia y Hermenéutica”, Oficio. Revista de Historia e Interdisciplina, № 6, p. 78.
} 
narración entendida, por el filósofo galo, como la raíz de la conciencia histórica ${ }^{15}$. Sin estar necesariamente en conexión con los presupuestos (que creo) en extremos subjetivistas y especulativos de las llamadas "presencias" del pasado -la "experiencia sublime" en Ankersmit, por ejemplo-, el uso que esta investigación hace de la propuesta ricoeuriana no deja de estar conectado con la epistemología de la historia como uno de los tipos de relaciones con el pasado (búsqueda de conocimiento) que establece el profesional de la historia ${ }^{16}$. La HTP, como otros enfoques historiográficos, no deja de estar sujeta a ese pacto tácito de verdad entre historiador y lector ${ }^{17}$.

Cuando se acude a dicha noción es para subrayar un problema de la experiencia histórica del sujeto historiador, una marca que lleva desde su propia historicidad en un marco social mayor. Esta investigación asume que todo pasado se ha ido, no vuelve. A decir de Ricoeur, reflexionar acerca del pasado nos lleva al problema de la memoria como matriz de la historia, lo cual en última instancia nos remite a lo planteado por Aristóteles cuando expresó que "la memoria es del pasado", asunto que el filósofo francés desarrolló desde el enigma de la presencia de la ausencia en su fenomenología de la memoria como apertura para la epistemología de la historia ${ }^{18}$. Con todo, lo que se resignifica en el lenguaje son experiencias que siempre están atadas a otros presentes, por lo tanto, no pueden existir experiencias sublimes o pasados que hacen "presencias". En este punto coincido con Kalle Pihlainen (en su valoración de la epistemología de la historia ciertamente no, pero eso escapa a los objetivos de este trabajo), uno de los teóricos más importantes del constructivismo narrativo desde la recepción de Hayden White, quien plantea que toda discusión acerca de las presencias del pasado son estériles en la medida que no puede haber presencia de algo ausente, resultando mucho más importante la discusión acerca del sentido histórico de aquello que se experiencia con respecto al pasado ${ }^{19}$. Este trabajo está en esa línea, por cierto.

Aquello que se plantea con la experiencia del historiador del tiempo presente como un problema temporal, apunta a lo que Ricoeur desarrolló desde la problematización de la condición histórica: "el movimiento de la filosofía crítica a la filosofía ontológica de la historia se imprime justamente en el término mismo de historicidad" ${ }^{20}$, lo que guarda directa relación

\footnotetext{
${ }^{15}$ Ricoeur, Paul. 1985. Temps et récit III. Le temps raconté, Paris, Seuil, p. 385.

${ }^{16}$ Tamm, Marek. 2014. "Truth, Objectivity and Evidence in History Writing", Journal of the Philosophy of History, Vol. 8, pp. 265-290.

17 "El problema de la representación del pasado por los historiadores puede enunciarse en términos de un pacto tácito que se establece entre el lector del texto histórico y el autor. El primero espera que se le proponga un "relato verdadero" y no una ficción. El segundo tiene entre manos el problema de saber si la escritura de la historia puede respetar ese pacto, cómo puede hacerlo y hasta qué punto", en Ricoeur, Paul. 2000. "L'écriture de l'histoire et la représentation du passé" Annales 55, №4, p. 734.

${ }_{18}$ Ricoeur, Paul. 2000. La mémoire, I'histoire, l'oubli, París, Seuil, pp. 8-25.

19 Kalle Pihlainen, 2019. La obra de historia. Constructivismo y política del pasado, Santiago, Palinodia, pp. 197-229.

${ }^{20}$ Ricoeur, La mémoire, l'histoire, l’oubli, p. 461.
} 
con la orientación temporal como sustrato antropológico de la existencia humana. Si damos por cierto esto, debemos asumir que toda tarea historiográfica asume un problema de sentido histórico. Asunto al que volveremos.

Entones, ¿qué razones se pueden esgrimir para conectar la HTP una experiencia intelectual con respecto al objeto de estudio? Veamos.

Julio Aróstegui explica que la HTP corresponde a un enfoque historiográfico comprendido desde el concepto de "historia vivida" ${ }^{21}$. El historiador español hizo énfasis en el análisis histórico de la realidad social y cultural asociado a la coetaneidad entre vivencia e historia, aquella experiencia que se puede escuchar de los testigos, asumiendo el problema generacional de la memoria como uno de sus puntos más importantes. Por otro lado, Henry Rousso plantea que la HTP se alza desde la "última catástrofe", en otras palabras, de la fuerza de ciertas realidades factuales que por su impacto desembocaron en acontecimientos que una y otra vez vuelven simbólicamente (resignificados) sobre el presente, inscribiendo este fenómeno dentro del régimen de historicidad contemporáneo definido por Hartog: "nuestro régimen de historicidad se define, en gran parte, por la dificultad de superar el recuerdo de las recientes grandes catástrofes, y por ende de restablecer una cierta continuidad histórica de una más larga duración" 22. Muchos años antes, el mismo Rousso había definido esto como los "los pasados que no pasan", lo que luego desembocaría en pugnas acerca del control e interpretación de la memoria social, aquello que la historiografía del tiempo presente llama "luchas por la memoria" ${ }^{23}$. Buena parte de los historiadores que han reflexionado acerca de este tipo de escritura de la historia coinciden en que es la coetaneidad entre historiador y pasado reciente, junto con la valoración del testimonio oral, lo que asigna nuevo valor a esta forma de escribir la historia.

Siguiendo el argumento de Rousso, la fuerza del recordar hechos pasados en la memoria social, y con ello en el trabajo historiográfico, corresponde a lógicas relacionadas con la representación de acontecimientos límites: dictaduras, genocidios y otros fenómenos sociales que asociamos, directa o indirectamente, a la experiencia del trauma ${ }^{24}$. Estos problemas han sido tratados por la literatura especializada como trabajos y deberes de memoria y justicia, estableciendo una evidente relación política con el pasado. Incluso se ha llegado a establecer

\footnotetext{
${ }^{21}$ Aróstegui, Julio. 2004. La historia vivida. Sobre la historia del tiempo presente, Madrid, Alianza, pp. 52-102.

22 Rousso, Henry. 2018. La última catástrofe. La historia, el presente, lo contemporáneo, Santiago, Editorial Universitaria, p. 26.

${ }^{23}$ Allier, Eugenia y Crenzel, Emilio (coord.), The Struggle for Memory in Latin America: Recent History and Political Violence, US, Palgrave Macmillan; Winn, Peter, Stern, Steve, Lorenz, Federico y Marchesi, Aldo. 2014. No hay mañana sin ayer. Batallas por la memoria histórica en el Cono Sur, Santiago, LOM.

24 Veto, Silvana. 2011. "El Holocausto como acontecimiento traumático. Acerca de la incorporación del concepto freudiano de trauma en la historiografía del Holocausto", Revista de Psicología № 20 vol. 1, pp. 127-151; LaCapra, Dominick. 2005. Escribir la historia, escribir el trauma, Buenos Aires, Nueva Visión.
} 
el problema de la memoria, en conjunto con el trabajo del recuerdo hacia fenómenos dolorosos y criminales -en vías de reparación, justicia y lucha contra el olvido-, como realidad global, conectándola por cierto con el régimen de historicidad el cual tendría el mismo carácter ${ }^{25}$.

El siglo XX fue, sin lugar a dudas, un tiempo en el que se vieron sucedidos una serie de acontecimientos violentos generadores de este tipo de realidades, donde el Holocausto ha tomado la bandera representativa (sean históricas o literarias). Al respecto, no debemos olvidar lo que Tony Judt aclaró: la memoria del Holocausto no se presenta en los años posteriores a 1945, es un fenómeno que germinó en los años ochenta y que es posterior a 1989 cuando arremete con fuerza en la historiografía ${ }^{26}$, año que no es menester presentar, y que coincide con lo que Hartog denomina el momento iniciador, simbólicamente, del régimen de historicidad presentista. Cabe recordar también lo que el historiador alemán Lucian Hölscher demostró con respecto a la fuerza detonadora en la percepción del tiempo histórico después de terminada la Primera Guerra Mundial, explicando que para la generación que la experimentó el resultado fue una verdadera "tormenta existencial [...] que puso patas arriba la experiencia del tiempo"27.

Siguiendo esta línea argumentativa, Hartog denomina palabras o ideas fuerza características de nuestro presente, todos ellos conceptos ineludibles para la comprensión de lo contemporáneo: memoria, conmemoración, patrimonio, identidad, crímenes contra la humanidad, víctima y testigo ${ }^{28}$. La sola evocación de ellas invita a pensar la HTP desde la memoria y el dolor, desde huellas de memorias heridas, afectadas por el pasado ${ }^{29}$, problema que como se verá, no corresponde a una relación teleológica con el pasado, sino que desde aquello que el pasado hace a las personas. Una relación de dependencia, como se verá más adelante.

A medida que Pierre Nora publicaba sus voluminosos Lugares de memoria (1984-1992), se ponía en práctica algo que para la ortodoxia historiadora del siglo XX no era costumbre: ocupar las memorias sociales como herramientas para explicar la historia, en este caso, de Francia. Para el autor francés, dicho siglo propiciaba una historicidad que terminaría inundando irremediablemente la tarea del historiador: las múltiples memorias de miles de sujetos que

\footnotetext{
25 Rousso, Henry. 2005. "Hacia una globalización de la memoria", Nuevo Mundo Mundos Nuevos. Puesto en línea el 18 septiembre 2015, (consultado el 14 diciembre 2019). http://nuevomundo.revues.org/68429

26 Judt, Tony. 2006. Postguerra. Una historia de Europa desde 1945, Barcelona, Taurus, pp. 1145-1183.

27 Hölscher, Lucian. 2013. "Mysteries of Historical Order: Ruptures, Simultaneity and the Relationship of the Past, the Present and the Future", en Lorenz, C. y Bevernage, B. (eds), Breaking up Time: Negotiating the Borders between Present, Past and Future, Göttingen, Vandenhoeck \& Ruprecht, p. 148.

${ }^{28}$ Hartog, Croire en l' histoire, p. 49.

${ }^{29}$ Somos conscientes de una discusión que todavía no está zanjada: ¿debe la HTP ser solamente asociada a pasados traumáticos? Es una pregunta por resolver. Para efectos de este trabajo se circunscribe HTP en relación a pasados traumáticos y violentos bajo las tesis ya mencionadas. Pero, un historiador que hace historia política del proceso constituyente actual en Chile, acaso ¿no hace historia política del tiempo presente?
} 
llevan marcado un "pasado que no pasa", estableciendo una nueva relación historia/memoria no apreciada por los rescates orales de historiografías pasadas. El análisis propuesto por Nora -mirada diacrónica puesta sobre los efectos más que en los orígenes (su historia en "segundo grado") - y una serie de otros intelectuales desde la década de los ochenta del siglo pasado, trajo a colación una nueva conciencia historiográfica, generadora de pugnas y disputas entre historia y memoria ${ }^{30}$.

Paul Ricoeur publicó La memoria, la historia, el olvido en el año 2000. Para muchos, un verdadero testamento intelectual que vino a sellar una vida completa dedicada a la reflexión filosófica. Dicha obra nació justamente al alero de un "momento memorial" agudo de la sociedad francesa ${ }^{31}$. El mismo Ricoeur lo expresa al comenzar la obra:

"La presente investigación es fruto de varias preocupaciones: unas privadas, otras profesionales y otras que llamaré públicas (...) Preocupación pública: me quedo perplejo por el inquietante espectáculo que dan el exceso de memoria aquí, el exceso de olvido allá, por no hablar de la influencia de las conmemoraciones y de los abusos de la memoria $-y$ de olvido. En este sentido, la idea de una política de la memoria justa es uno de mis temas cívicos reconocidos." ${ }^{32}$

En dicha obra Ricoeur condensó una fenomenología de la memoria, una epistemología de la historia y una hermenéutica de la condición humana ${ }^{33}$ en vías de un trabajo de la memoria bajo la lupa de la operación historiográfica evocada por De Certeau. Ricoeur partía de una hipótesis complementaria a la clásica tesis de la memoria social en Halbwachs: la atribución múltiple de la memoria. Ante la pregunta ¿quién recuerda?, Ricoeur contestó: yo, tú, nosotros y todas las personas gramaticales ${ }^{34}$. Fundaba así una pragmática de la memoria (su ideal de memoria justa) en una doble articulación: el regreso del recuerdo y la búsqueda de memoria, con la articulación de la memoria individual y la memoria colectiva. En el filósofo francés, la operación historiográfica introduce justicia a la memoria colectiva, entendida esta como "vicaria" del pasado bajo la lógica del concepto de representancia (représentance) ${ }^{35}$, noción creada por Ricoeur para conjugar epistemología del conocimiento histórico y una ontología de la condición histórica.

\footnotetext{
${ }^{30}$ Nora, Pierre. 2009. Pierre Nora en Les Lieux de mémoire, Santiago, LOM, p. 21.

${ }^{31}$ Dosse, François. 2013. Paul Ricoeur. Los sentidos de una vida (1913-2005), Buenos Aires, Fondo de Cultura Económica, p. 698.

32 Ricoeur, La mémoire, l'histoire, l'oubli, p. 1

${ }^{33}$ Dosse, François y Goldenstein, Catherine. 2013. Paul Ricoeur: penser la mémoire, París, Seuil, p. 9.

${ }^{34}$ Ricoeur, La mémoire, I'histoire, l'oubli, p. 734.

35 Íbid., pp. 359-369. El concepto es utilizado por Ricoeur por primera vez al terminar Tiempo y narración III (1985) en el contexto del problema de la conciencia histórica. Ahora es retomado por su autor para profundizar aspectos de la comprensión y explicación de la representación historiadora. Hay que hacer notar que pocas veces un filósofo hizo tantos aportes a la disciplina preocupada del pasado, quizás la noción de representancia sea su punto más alto.
} 
Según el historiador español Santos Juliá, la problemática de la memoria desde finales del siglo XX es una de las principales derivaciones de la "crisis de la historia". La memoria, para Juliá, se alza como producto de los llamados estudios culturales: giros hacia el sujeto y hacia la impronta del lenguaje (giro lingüístico), asuntos que han llevado a ciertas improntas: producción de identidades colectivas (con la activa participación de los Estados), la arremetida valórica de la justicia en los procesos históricos, sobre todos los de crímenes contra la humanidad y hasta la relación de estos con los estudios postmodernos ${ }^{36}$. Ignacio Peiró, por otro lado, esgrimió que los agitados climas de opinión creados desde las conmemoraciones y procesos judiciales por los crímenes contra la humanidad en Francia, Alemania, Israel e Italia (al autor le falta nombrar una serie de procesos similares en América Latina) y la consolidación institucional de la HTP, han editado un alud de textos y libros que historizan la memoria en la "era de la catástrofe" ${ }^{37}$. Otra respuesta al auge de la memoria en nuestros tiempos nos la entrega Enzo Traverso invocando a Walter Benjamin desde el uso de los conceptos de experiencia transmitida y experiencia vivida. Bajo la primera, propia de las sociedades tradicionales, la experiencia se va forjando y transmitiendo de generación en generación de manera espontánea, formando a la vez identidades de grupos y sociedades en larga duración; en la segunda, propia de nuestra contemporaneidad, corresponde a una experiencia volátil, efímera y frágil, típica de las sociedades individualistas. Para Traverso, la obsesión por la memoria se explicaría en la crisis de la experiencia transmitida ${ }^{38}$, asunto que recuerda a Bauman y su modernidad "líquida".

Es en este contexto, el de la memoria como problema histórico, donde se inscribe la reflexión disciplinar por la HTP. Su propia representación del pasado corresponde a un tipo de acontecimiento que es menester comprender, toda vez que damos por cierta la máxima que entiende que "los textos históricos, al fin y al cabo, pueden constituirse en sí mismos como testimonios y manifestaciones de una cultura determinada" ${ }^{39}$. Sabemos que la historiografía, a escala global, ha experimentado una serie de transformaciones a lo largo del siglo XX que ha devenido en una diáspora de posibilidades de comprensión del pasado. En lo que respecta a este trabajo, me interesa resaltar un cambio fundamental, a saber, que no podemos pasar por alto la fuerza de lo contemporáneo, en particular, su historicidad o relaciones sociales del tiempo que todo observador del pasado imprime, de manera indirecta, a su escrito histórico. Las y los historiadores miran y escrutan el pasado desde un presente que lo configura

\footnotetext{
36 Juliá, Santos. 2011. Elogio de Historia en tiempos de memoria, Madrid, Marcial Pons, pp. 132-133.

37 Peiró, Ignacio. 2004. "La consagración de la memoria: una mirada panorámica a la historiografía contemporánea", Ayer № 52, p. 198.

38 Traverso, Enzo. 2007. "Historia y memoria. Notas para un debate", en Historia reciente. Perspectivas y desafíos para un campo en construcción, Buenos Aires, Paidós, pp. 68-69.

${ }^{39}$ Aurell, Jaume. 2005. La escritura de la memoria. De los positivismos a los postmodernismos, Valencia, Universidad de Valencia, p. 21.
} 
socialmente, no para desfigurarlo, sino para darle sentido desde distintos campos de experiencia, usando la clásica denominación de Koselleck.

Siguiendo esta línea, la relación entre escritura de la historia del tiempo presente e historicidad, encuentra en nuestra lectura de la filosofía de Paul Ricoeur una herramienta central. En particular, lo referente a la denominada condición histórica ${ }^{40}$, donde se propone pensar la HTP como un problema de sujetos (los historiadores del tiempo presente) "afectados por el pasado", asunto que desarrollaremos vinculándola con la tesis del sentido histórico en la teoría de la historia de Jörn Rüsen. De esta manera, y bajo esta lógica, el historiador de lo contemporáneo se posiciona tanto testigo de su época como marcado, afectado por los acontecimientos que, o bien ha vivido directamente, o lo han determinado por un asunto generacional de proximidad y empatía ante ciertos momentos históricos: como "testigo secundario" ${ }^{41}$. Visto así, el historiador entra en el análisis de construcción del conocimiento del pasado que él mismo proyecta transformándose en un "vector de memoria" 42 . A estas marcas del pasado próximo se refería Hobsbawm cuando argumentaba, en la introducción al tercer tomo de su clásica trilogía, la diferencia en la "relación con el pasado" entre las generaciones que sucedieron 1914 con generaciones remotas. El historiador británico, sin entrar en detalle, adelanta algo crucial para nuestra investigación, que las relaciones con el pasado dependen del vínculo que los una, puesto que a diferencia del historidor/a de tiempo presente, aquel que escruta pasados lejanos guarda una relación distinta (incluso no emocional) con su objeto de estudio:

"no pretendo afirmar que el pasado más remoto carezca de significación para nosotros, sino que nuestra relación con ese pasado es diferente. Cuando se trata de épocas remotas sabemos que nos situamos ante ellas como individuos extraños y ajenos (...) Cuando esas épocas son cronológicas, geográficas o emocionalmente lo bastante remotas, sólo pueden sobrevivir a través de los restos inanimados de los muertos: palabras y símbolos escritos, impresos o grabados; objetos materiales o imágenes."43

De esta manera, Ricoeur extrae de la experiencia ontológica del padecer y sufrir una estructura primitiva: el ser-afectado-por-el-pasado, centro neurálgico de la condición histórica y su relación con la conciencia histórica: "somos agentes de la historia sólo en la medida en que somos sus pacientes. Las víctimas de la historia y las innumerables multitudes que, aún hoy, la

\footnotetext{
${ }^{40}$ Ricoeur, La mémoire, l'histoire, l'oubli, p. 461.

${ }^{41}$ LaCapra, Dominick. 2009. Historia y memoria después de Auschwitz, Buenos Aires, Prometeo, p. 35.

42 Rousso, Henry. 2007. "La trayectoria de un historiador del tiempo presente", en Anne Pérotin-Dumon, Historizar el pasado vivo en América Latina, p. 5. En www.historizarelpasadovivo.cl (consultado el 25-7-2019); Ovalle, Daniel. 2018. “"El historiador del Tiempo Presente: ¿vector de conciencia histórica?" en Moreno, Rodrigo; Corti, Paola; Widow José Luis (editores), La utilidad de la Historia, Asturias, Trea. pp. 315-328.

${ }^{43}$ Hobsbawm, Eric. 2003. La era del Imperio 1875-1914, Barcelona, Crítica, p. 12.
} 
sufren mucho más de lo que la hacen, son los testigos por excelencia de esta estructura mayor de la condición histórica" ${ }^{44}$. Al tomar por herramienta esta noción filosófica, la operación historiográfica del tiempo presente se entiende desde la vivencia e historicidad de sujeto historiador con respecto del pasado que intenta escrutar, relación distinta del historiador de tiempos remotos -tal como expresaba Hobsbawm- quien no puede acceder a un tipo de memoria quizás más directa (llámese su propia experiencia o el registro oral de otros). El historiador del tiempo presente es testigo entonces del dolor, del trauma y de la última catástrofe que bajo la operación historiográfica intenta representar, pero ahora desde un lazo distinto a esos pasados remotos. El ser afectado por el pasado es una herramienta ontológica que no se queda solo en el plano filosófico, sirve para complejizar nuestra disciplina rompiendo con la clásica mirada de la distancia temporal con respecto al objeto histórico. No es solo la "última catástrofe" la generadora de esta nueva relación con el tiempo que ha devenido en esos "pasados que no pasan", más bien el efecto de ese acontecimiento sobre los sujetos. El acontecimiento es el impulso evocador, pero son las marcas del pasado en la memoria personal y colectiva las generadoras de una posición historiográfica renovada que ha roto con la postura clásica de la distancia temporal para una "objetiva" representación historiadora. Queda ahora desarrollar la relación de esta clave ontológica en la HTP desde la óptica de la temporalidad (estructural).

\section{Presentismo e Historia del Tiempo Presente}

¿Pueden los cambios producidos en la manera en que los historiadores escrutan el pasado responder a la relación que tienen éstos con el tiempo? En otras palabras, ¿es escrita la historia en relación al orden de historicidad en que los historiadores miran el pasado? En la primera parte de este trabajo se ha argumentado la existencia de un fenómeno intelectual, el del estudio de la memoria y su articulación historiográfica. Ahora queda por argumentar cómo es que ese fenómeno responde también a una nueva perspectiva temporal que ha roto los lazos del historicismo decimonónico tan presente en parte del siglo XX. Como ha expresado Barash, se ha pasado del tiempo del pasado histórico al tiempo de la memoria, lo cual nos obliga a replantear nuestra experiencia temporal e histórica ${ }^{45}$.

Desde la publicación entre 1983 y 1985 de los tres tomos de Tiempo y narración de Ricoeur, la disciplina preocupada del pasado no puede objetar carencia en la reflexión acerca del tiempo ${ }^{46}$. Sabemos con su filosofía del lenguaje de la presencia del tiempo en la medida que

\footnotetext{
${ }^{44}$ Ricoeur, Temps et récit III, p. 391. Para una comprensión más completa ver 391-414.

${ }^{45}$ Barash, Jeffrey. 2016. Collective memory and the historical past. Chicago, University of Chicago Press.

46 Un primer intento por desarrollar la problemática del tiempo en la obra de Ricoeur la he trabajado en Ovalle, Daniel. 2019a. "Sujeto histórico y temporalidad en Paul Ricoeur hasta Temps et récit como aportes conceptuales para la teoría de la historia", Cuadernos de Historia Cultural, № 8, pp. 10-33.
} 
narramos discursos ficcionales y verdaderos. Hay tiempo humano en la medida de la narración y esta se encuentra supeditada bajo la dialéctica de múltiples "campos de experiencia" y "horizontes de expectativas", herramienta kosellequiana que Ricoeur tomó y validó en el tercer tomo de su obra para introducir el problema de la conciencia histórica. En la interminable dialéctica de la narración se constata la construcción de un tercer tiempo, el tiempo histórico, distinto del tiempo cósmico (los astros y el calendario) y el tiempo íntimo (fenomenológico de todo sujeto). La existencia de un régimen de historicidad específico para la comprensión de la HTP, viene a ser objeto de estudio bajo una tesis bastante aceptada: el régimen moderno de historicidad o historicismo, declinó luego de las dos guerras mundiales, para dar paso en los últimos veinte años del siglo pasado a una mutación en la historicidad vista desde un plano estructural. Ese régimen moderno de historicidad es la confianza en el futuro, tan propia de la cultura capitalista europea del siglo XIX y que el imperialismo repartió por el mundo ${ }^{47}$. Hans Ulrich Gumbrecht define el modus operandi de lo que llama el cronotopo historicista en cinco puntos claves: primero, el pasado siempre es otro, está detrás y tiende a desvanecerse; segundo, el futuro es siempre un horizonte abierto a las posibilidades; tercero, el presente es siempre un momento corto y casi imperceptible; cuarto, el presente es la posibilidad de auto comprensión humana bajo su lógica de potencia; y quinto, por rápido o lento que pueda parecer, todo fenómeno humano está supeditado, bajo esta lógica, a la transformación ${ }^{48}$.

La relación que hacemos entre HTP y régimen de historicidad, no se esgrime bajo este cronotopo descrito por el teórico de la literatura norteamericano. Se enmarca dentro del auge por la memoria social, por el trauma de pasados que no pasan, según la famosa expresión de Rousso. Lo explicaremos.

Si existen memorias sociales bajo todas las figuras gramaticales también lo existe en la construcción de ese tiempo histórico o régimen de historicidad. Allí radica la operatividad de recurrir a la herramienta heurística de los regímenes de historicidad en Hartog, quien explica su articulación de la siguiente manera:

"En cuanto se trata del tiempo, nunca tenemos acceso a nada que no sean experiencias del tiempo, de las cuales, a decir verdad, todo en una cultura, siempre que la interroguemos desde este ángulo, puede suministrar un indicio o testimonio: desde la producción

\footnotetext{
${ }^{47}$ Coincidimos con uno de los evaluadores de este artículo, en que es sumamente problemático asumir todo régimen de historicidad bajo un plano global. Si bien este trabajo no puede hacerse cargo de semejante problema, pues debemos considerar las múltiples diferencias culturales con Asia, África y Oceanía, es mejor circunscribir los regímenes de historicidad moderno y presentista pensando en occidente. Con todo, el capitalismo global actual, en su faceta financiera, al menos debería hacernos preguntar si acaso - desde un plano estructural - ¿no comparte buena parte del mundo una lógica temporal homogénea? Es una pregunta que, por cierto, asume objetivos que no son parte de este artículo.

48 Gumbrecht, H. 2014. "The Future of Reading? Memories and Thoughts Toward a Genealogical Approach" Boundary 2, 41, № 2, pp. 107-108.
} 
intelectual más elaborada, hasta el objeto más ordinario de la vida cotidiana, pasando por mil sutilezas reflexivas. A partir de las experiencias nos elevamos a las formas y los modos de las temporalidades, que son elaboraciones, generadas por los propios contemporáneos para orientarse en el tiempo, en su tiempo: para comprenderlo y decirlo, con sus palabras y sus conceptos, sus imágenes y sus relatos, en suma, movilizando todos los recursos de su cultura pasada y presente [...] Entre las referencias, en primer lugar están las categorías del pasado, del presente y del futuro, cuyos contenidos así como las maneras de articularlos es decir, sus fronteras- han variado, según las épocas y lugares" ${ }^{\prime 9}$.

Visto así, y con respecto al problema aquí planteado -la relación historicidad y escritura de la historia del tiempo presente- Ricoeur aclara algo fundamental para efectos de nuestro objetivo de relacionar la escritura de la historia con la conciencia histórica "que la operación historiográfica procede de una doble reducción: la de la experiencia viva de la memoria y la de la especulación multimilenaria sobre el orden del tiempo" ${ }^{50}$.

La historia y su "pérdida de evidencia" -a decir de Hartog- en la concreción de verdades que cimienten un futuro plausible y esperado (crisis del futuro), ha traído como coletazo el boom de la memoria en los esfuerzos historiográficos ${ }^{51}$ y con ello, lo hemos dicho, la emergencia de la HTP. La presencia constante de los "lugares de memoria" nos hace prescindir de grandes narrativas, transformando la problemática de historia/memoria como un síntoma de un régimen moribundo de historicidad, en el cual el único referente es el presente, ya no el futuro, como sí lo fuera para la historiografía moderna. Sabemos que la conciencia se estructura temporalmente, con ello es imposible borrar el asidero del futuro. Lo que se recalca es una "opacidad" del futuro, una tendencia global a la inmediatez y desconfianza al porvenir en la degradación de la idea de progreso tal y como se entendió en la primera modernidad, para decirlo en términos sociológicos. Cuando decimos un régimen moribundo de historicidad nos referimos a la disolución de las diferencias entre pasado, presente y futuro, tal como las heredamos del régimen moderno de historicidad, donde "el tiempo se conceptualizó como un movimiento rápido, simbolizado por una flecha que se mueve del pasado al futuro" ${ }^{52}$.

\footnotetext{
${ }^{49}$ Hartog, François. 2013. "The modern régime of historicity in the face of two world wars", en Breaking up Time. Negotiating the Borders between Present, Past and Future, Göttingen, Vandenhoeck \& Ruprecht,p. 124.

50 Ricoeur, La mémoire, I'histoire, l'oubli, p. 200.

${ }^{51}$ Hartog, François. 2005. Évidence de l'histoire. Ce que voient les historiens, París, Ed. EHESS, pp. 205-295. Jay Winter (2001) evoca el llamado "boom de la memoria", ver "The generation of memory: Reflections on the "Memory boom" in contemporary historical studies", Canadian Military History Vol. 10 № 3, pp. 57-66 y Spiegel, Gabrielle. 2016. "L'expérience entre histoire et mémoire" en L'expérience historiographique. Autor de Jacques Revel, París, Éditions de I'EHESS.

52 Aleida Assmann. 2019. "A Creed That Has Lost its Believers? Reconfiguring the Concepts of Time and History", Tamm, Marek y Olivier, Laurent (eds.). 2019. Rethinking Historical Time: New Approaches to Presentism, London, Bloomsbury, p. 208.
} 
Entonces, ¿qué es el presentismo y cuál es la relación que vemos con la HTP? La correlación se enmarca dentro de los aportes hechos por Hartog quien, al detener en el estudio de la comprensión de la historicidad, ha propuesto el concepto de "regímenes de historicidad" como herramienta heurística, correspondiente a una categoría analítica para hacer inteligible las distintas experiencias sociales del tiempo, tesis expuesta en su libro Régimes d'historcité. Présentisme et experience du témps del año 2003, y trabajada luego en tres libros complementarios y necesarios para seguir la huella argumentativa de la tesis: Évidence de I'histoire. Ce que voient les historiens (2005), Croire en l'histoire (2013) y Chronos. L'Occident aux prises avec le temps (2020). Hartog explica que "el régimen de historicidad se presenta como un instrumento para interrogar las diferentes experiencias del tiempo, las crisis del tiempo (...) Vamos a entender por regímenes de historicidad las modalidades de articulación de las categorías pasado, presente futuro" ${ }^{53}$.

Desde una renovada mirada estructuralista de larga duración histórica, tres son los regímenes desde la antigüedad hasta el siglo XXI y tres las relaciones de éstos con el pasado: régimen antiguo de historicidad, donde la historia es magistra vitae (pasadista, tiempo cíclico desde la confianza en que del pasado se podrán sacar lecciones); régimen moderno de historicidad, desde el siglo XVIII hasta el XX caracterizado por la relación del pasado como herramienta de triunfo (progreso) en dirección del futuro (futurista); y el presentismo, desde finales del siglo XX (1989 como año símbolo), relación social del tiempo marcado por la aceleración de la vida y una relación del pasado y el futuro para y en vías del presente. Un presente omnipresente.

Hartog, siguiendo a Koselleck, diferencia tipologías de la experiencia social del tiempo. EI "régimen moderno de historicidad", configurado desde la Revolución Francesa hasta la caída de la Unión Soviética (1789-198954), presenta experiencias que desde el siglo XVIII representan símbolos culturales plasmados en las filosofías de la historia confiadas de un futuro promisorio o en la confianza en el progreso (pensemos en Comte, Marx y otros). Bauman lo ha mostrado, desde la sociología al asociar modernidad con la idea de emancipación, el telos del cambio histórico ${ }^{55}$.

Conceptualmente la idea de historia, configurada desde la antigüedad como magistra vitae bajo la clásica expresión de Cicerón, es absorbida por la nueva historicidad moderna que se abre al futuro (primero lo hizo la tradición judeo-cristiana estableciendo una temporalidad

\footnotetext{
53 Hartog, François. 2010. "Historicité / régime d'historicité", en Delacroix, Dosse, García y Offenstadt (Dir.). 2010. Historiogrphies II. Concepts et débats, París, Gallimard, p. 766.

${ }^{54}$ El autor es claro en señalar que tanto la Revolución Francesa como la caída del Socialismo representan figuras simbólicas de la experiencia temporal, lejos está la idea de una cronología. Es más, los distintos regímenes de historicidad pueden convivir en pugna y no representan estadios objetivos.

${ }^{55}$ Bauman, Zygmunt. 2015. Modernidad líquida, México, Fondo de Cultura Económica, pp. 21-58.
} 
lineal y teleológica, pero de la salvación del alma), asunto que Koselleck puntualizó desde el siglo XVIII. El mismo Hartog recuerda, siguiendo a De Certeau, que la operación historiográfica moderna debe ser comprendida bajo el signo de la separación y quiebre del pasado y del presente, entendida como desarrollo y proceso. Es el futuro, en el régimen moderno de historicidad, el nudo de la historiografía. Si antes las lecciones venían de los ejemplos que daba el pasado, ahora los entregaba el futuro. De esta manera, existió una estrecha relación entre historia, política y tiempo. Relación que vista en perspectiva, condujo las condiciones de posibilidad (epistemología) de la nueva ciencia histórica.

Por otro lado, el régimen presentista permite pensar una nueva relación social de la temporalidad (y por tanto de la apreciación social de la historia), en donde el futuro parece no presentar garantías, donde los proyectos son de corto plazo (súmense al fin de las ideologías el debilitamiento del Estado-Nación) y donde el presente parece extender fenomenológicamente su presencia ${ }^{56}$ y estar irreductiblemente vinculado con una relación entre pasado y presente distinta a la que mostrara el quiebre moderno allá por el siglo XIX. Al respecto, dice Hartog:

"La Memoria es esa palabra maestra que permite decir más: ella es un derecho, un deber, un arma. Duelo, trauma, catarsis, trabajo de memoria y piedad le hacen compañía [...] Ella es claramente una alternativa a una historia que ha fallado, que ha muerto: una historia de vencedores y no de víctimas, de olvidados, de dominados, de minorías y de colonizados. Una historia encerrada en la nación [...] Participa además de una configuración más vasta al lado de Patrimonio, Conmemoración e Identidad. Estas otras palabras maestras, tan diferentes ya sea por sus historias, sus registros y sus usos anteriores, se conectan unas a las otras y hacen de ahí en adelante un sistema. Tienen por rasgo común partir de un malestar del presente y traducir, bien que mal, nuevas relaciones temporales. Eso que he Ilamado (a título de hipótesis) presentismo, es ese momento de un presente omnipresente, marcado por la clausura del futuro y por un pasado que no pasa" ${ }^{57}$.

Puesto a prueba, ahora bajo las formas de escritura de la historia, los regímenes de historicidad proyectados en "regímenes historiográficos", podrían entregarnos luces acerca de cómo los historiadores llevan a cabo la operación historiográfica desde la misma comprensión de lo que entienden por el concepto de historia, no solo para dar cuenta de ello, sino en vías de su comprensión, entendiendo que el trabajo del historiador es también parte de un entramado social que exige ser evaluado históricamente. Como lo ha propuesto también Mudrovcic, las distintas modalidades temporales deberían contar -sin tener una correlación mecánica- con

\footnotetext{
56 Hölscher, Lucian. 2014. El descubrimiento del futuro, Madrid, Siglo XXI, pp. 215-227.

57 Hartog, François. 2009. “Historia, memoria y crisis del tiempo”, Historia y Grafía № 33, pp. 128-129.
} 
un lazo común entre experiencias del tiempo y escritura de la historia ${ }^{58}$. A diferencia de lo planteado en el primer apartado, ahora la óptica está puesta desde lo estructural.

Tomado de Koselleck las nociones de "campo de experiencia" (el pasado en el presente) y "horizonte de expectativas" (el futuro en el presente), el nuevo régimen de historicidad se caracteriza por una especie de fusión entre estas dos ideas metahistóricas. Si desde el siglo XIX las sociedades comprendían su historicidad entre experiencia y horizonte como fenómenos complementados (y separados), en el presentismo el horizonte de expectativas entra en una especie de nebulosa. Se quiebra lo que antes se complementaba. Esta idea está ligada a fenómenos globales de gran importancia, como lo son la globalización de la economía neoliberal (con sus respectivas crisis económicas mundiales), el debilitamiento del Estado nación, la creciente inseguridad de la vida material, el cambio climático, etc. La idea de "crisis del futuro" evocada por Krzysztof Pomian en 1989 tiene todavía vigencia ${ }^{59}$. Como expone Mudrovcic: "Carecemos de la confianza en el progreso, topoi común de la época moderna. Se pasó de una promesa de progreso y una creencia en futuros promisorios a un mundo caracterizado por la precariedad y la inseguridad. Tenemos un déficit de futuro" ${ }^{60}$. A este respecto, Manuel Cruz aduce con respecto a las múltiples movilizaciones sociales en contra de las políticas de Estados que parecen no poder contrarrestar el malestar social: "han sido despojadas de todo futuro y las únicas opciones que les quedan es impugnar el presente, agrietar la asfixiante realidad" ${ }^{\prime 1}$.

Este mundo presentista, en el cual el presente se ha transformado en la categoría fuerza, presenta una posibilidad de autorreflexión disciplinar, sobre todo si hacemos caso de lo que significa vivir bajo una historicidad como ella:

"vivimos inmersos en acontecimientos que vienen unos tras otros pero que no tienen relación entre ellos, y lo único que se puede hacer es actuar rápido, reaccionar. Detrás de ello está la certeza de que hemos entrado en una era de catástrofes [...] Y lo único que esperamos de los políticos es la rapidez de su reacción, no sus propuestas ni capacidad de hacer. De modo que cuando acaba la catástrofe, esperamos de inmediato la catástrofe que vendrá. Así se vive el tiempo en un régimen de historicidad presentista" ${ }^{\prime 2}$.

\footnotetext{
58 Mudrovcic, "Regímenes de historicidad y regímenes historiográficos", p. 12.

59 Pomian, Krzysztof. 1989. "La crise de l'avenir" Le Débat № 7, pp. 5-17.

60 Mudrovcic, María Inés. 2015. "Crisis del futuro: política y tiempo" Ariadna histórica. Lenguajes, conceptos, metáforas №4, p. 100.

${ }^{61}$ Cruz, Manuel. 2012. Adiós historia adiós: el abandono del pasado en el mundo actual, Oviedo, Ediciones Nobel, p. 235

62 Aravena, Pablo. 2014. "François Hartog: la historia en un tiempo catastrófico" (entrevista), Cuadernos de Historia №41, p. 230.
} 
Como argumentan una serie de intelectuales, vivimos en tiempos en que el presente -por el efecto social de la relación que tienen las sociedades entre el pasado y futuro: la historicidad - parece expandirse mirando hacia el pasado de la memoria y temiendo al futuro. Este nuevo régimen de historicidad viene a ser una herramienta heurística para la comprensión de nuestras sociedades y por ende de cómo los historiadores de hoy escriben y miran hacia el pasado. Hartog es enfático: "Con el final del siglo XX, la historia parece haber pasado de la omnipotencia a la impotencia"63. La cita enmarca una idea que recorre todos sus últimos trabajos: la historia, esa idea moderna que Koselleck denominó como singular colectivo, la Historia (que apareciera en el siglo XVIII y que fuera el motor entre pasado y futuro), parece fundirse en la incertidumbre: la historicidad de hoy está lejos de esa Historia magistra vitae propia del régimen antiguo de historicidad (lejos también de su hermana cristiana magistra vitae aeternae) o de la idea de progreso ligada al régimen moderno. Dicho fenómeno tiene respuestas, entre ellas destacamos el ascenso de la memoria y con ella, la recuperación del testimonio y el acontecimiento en la configuración de la operación historiográfica.

Dicho esto, es necesario esbozar -aunque sea de manera muy rápida - una crítica a la tesis de Hartog y del presentismo, que dicho sea de paso, en nada cambia la relación aquí expuesta. Zoltán Boldizsár Simon esgrime recientemente la tesis de que nuestra contemporaneidad global vive tiempos de "cambios sin precedentes", algo distinto al presentismo, el cual sería válido acuñar si nos referimos a un tipo de relación temporal desde lo ideológico-político, no así con respecto a nuestras expectativas con la tecnología y los temores e incertezas que causa el cambio climático, por ejemplo, en la discusión del Antropoceno ${ }^{64}$. El gran aporte de Simon, a nuestro juicio, es complementar la tesis de Hartog con las discusiones acerca del posthumanismo y el cambio a escala planetaria-global ${ }^{65}$ con respecto a las repercusiones climáticas del capitalismo, argumentando que la sensibilidad histórica actual no dialoga con la visión moderna del proceso y desarrollo continuo. Una sensibilidad histórica que responde a un entramado humano-tecnológico-natural ${ }^{66}$, desde una experiencia histórica de reiterados

\footnotetext{
63 Hartog, Croire en l histoire, p. 29.

64 Simon, Zoltán. 2019. History in Times of Unprecedented Change. A Theory for the 21st Century, London, Bloomsbury, pp. 1-37. Las contribuciones más actuales para una complementación y/o crítica a la teoría del presentismo en Tamm, Marek y Olivier, Laurent (editores). 2019. Rethinking Historical Time: New Approaches to Presentism, London, Bloomsbury.

${ }^{65}$ Esta necesaria distinción no proviene de los trabajos de Simon. Dipesh Chakrabarty viene elaborando argumentos contundentes en relación al tiempo histórico y su correlato contemporáneo con los cambios a nivel planetario (distinto de lo global), como el del clima, ver Chakrabarty. 2019. "The Planet: An Emergent Humanist Category" Critical Inquiry № 46, pp. 1-31 y

66 Simon, Zoltán. 2020. The Epochal Event. Transformations in the Entangled Human, Technological and Natural Worlds, U.K, Palgrave Macmillan, p. 25. Agradezco personalmente a Zoltán que me haya hecho llegar de manera digital y desinteresada su último libro.
} 
"cambios sin precedentes" que terminan por configurar una experiencia de época que, sin lugar a dudas, se relaciona con eso que Chakrabarty expresa al comenzar su último libro:

"La pandemia actual, el auge de los regímenes autoritarios, racistas y xenófobos en todo el mundo, y los debates sobre las energías renovables, los combustibles fósiles, el cambio climático, los fenómenos meteorológicos extremos, la escasez de agua, la pérdida de biodiversidad, el Antropoceno, etc., nos indican aunque sea vagamente, que algo va mal en nuestro planeta y que puede tener que ver con las acciones humanas." ${ }^{67}$

Volviendo a lo nuestro, la relación con el pasado que establece el historiador del tiempo presente es sumamente distinta del que lo hace con respecto a un pasado que se ha ido, al cual puede "dar sepultura", como diría De Certeau. La HTP es una historia contemporánea al sujeto historiador. Nace de él la necesidad de comprensión bajo un tipo de relación con ese pasado que opera por el estar afectado. En este sentido, el problema de la verdad y la justicia deben ser asociados al tipo de "relaciones con el pasado" que el historiador del tiempo presente establece con el futuro, problema que se plantea en diálogo con la teoría de la historia propuesta por Herman Paul. De todos los tipos de relaciones con el pasado que el historiador holandés propone, la llamada "relación material" es aquella que, al no ser una relación de tipo teleológica, se configura no desde un telos sino que desde aquello que le reclamamos al pasado, como explica Paul: desde la "deuda y dependencia"68. Paul no centra su análisis bajo la órbita de la historia del presente ni sus desavenencias y diálogos con la memoria, no es ese su objetivo, lo que espera es dar cuenta de una holística teoría de la historia factible de aplicar a cualquier teoría de objetos. Coincido con el autor en que la relación de tipo material es la más problemática. Y esto debe ser explicado desde un punto de vista que Paul desliza, pero no profundiza: que las relaciones con el pasado son un conjunto de problemas temporales, y están regidas, por tanto, bajo la tensión entre lo que le pedimos y exigimos al pasado en conjunto con lo que esperamos del futuro. Las reclamaciones de verdad y justicia tan ligadas a la HTP y la justicia transicional son relaciones políticas y teleológicas con respecto al pasado, pues orientan una escritura de la historia hacia la reparación del daño, del dolor, del trauma de la catástrofe. Pero hemos querido sumar a esta óptica de análisis, que este entramado tiene su correlato desde un tipo de relación con el pasado (material) que responde a un problema ontológico: la afectación.

Llegado a este punto, dos preguntas se nos presentan ¿Existe novedad, para la operación historiográfica del tiempo presente, en el rol del testimonio (memoria del testigo, de la víctima) en comparación con la historiografía del régimen moderno de historicidad?; lo mismo para el

\footnotetext{
${ }^{67}$ Chakrabarty, Dipesh. 2021. The Climate of History. In a planetary age, Chicago, University of Chicago Press, p. 1. 68 Paul, Key Issues in Historical Theory, p. 34.
} 
caso del historiador, ¿tiene este y su trabajo un nuevo rol dentro del régimen presentista? Novedad en el uso del testimonio no, consideremos que esta ha sido una herramienta ocupada desde el nacimiento de la disciplina de los griegos en adelante ${ }^{69}$, sí desde la idea siguiente, y vaya acá nuestro aporte a la discusión: no es la noción del testimonio la novedosa, sino su uso en el contexto de una nueva relación social de las categorías temporales pasado-presentefuturo. Si griegos, romanos y medievales usaron los vestigios memoriales para construir representaciones históricas, lo hicieron en base a una relación con el pasado y el devenir donde la memoria era herramienta para la vida, donde esta aseguraba, luego, cierto futuro posible (terrenal o celestial), promisorio para el caso moderno, o de una memoria ejemplar para la vida en la antigüedad. Si consideramos que nuestro presente da cuenta de una nueva relación con esas categorías, la memoria a la que se acude es ahora producto de nuestra "marca del pasado doloroso". Hemos dicho con Ricoeur que la HTP debe ser vinculada a grupos de historiadores que han sido parte generacional de acontecimientos límites, todos ellos motores de un sentido histórico nuevo que pareciera estar en pugna, o a lo menos en discordancia, con lo que vive la sociedad presentista: una fascinación por el pasado pero desde el consumo de este, donde el patrimonio y los museos toman el papel relevante, no desde un sentido que alberge pasado para el presente y futuro ${ }^{70}$. Este fenómeno está ahora asociado a la reparación, la justicia y los peligros de la fragilidad de la memoria y el olvido. La HTP nos sirve como herramienta para un sentido histórico no solo de las víctimas, sino que podría incluso ser herramienta para la apertura de esa opacidad del futuro a la que nos hemos referido. Si ella asume esta historicidad presentista, donde el voraz capitalismo financiero y su globalización triunfan de manera acelerada en todo el orbe (dejando millones de damnificados y otros tantos muertos cada día), al historiar el tiempo presente, la voz del testigo sometida a la crítica historiográfica y por lo mismo bajo la lupa de la prueba documental, podría ser útil para el desarrollo de una "conciencia histórica" ${ }^{71}$ en un cuadro interpretativo del pasado que camina en dirección opuesta: desde la carencia de sentido del pasado para el presente (el consumo del pasado no es lo mismo) y la opacidad del futuro. Si aceptamos con Ricoeur que la memoria es matriz de la historia, y que todo documento es a fin de cuentas testimonio de memorias, sabremos que la historiografía bajo el régimen moderno de historicidad -y entiéndase bien, esta puede y debe comprenderse en pugna y contemporánea también a la HTP y presentismo- entendió el

\footnotetext{
69 Pasamar, Gonzalo. 2009. “Orígenes de la historia del presente. El modelo de los historiae ipsius temporis en los siglos XVI y XVII", Tiempos Modernos №19.

70 "un presente incomprensible, una realidad inconcebible, un mundo naturalizado (que), solo aceptan viajar al pasado de visita. La vieja expectativa de que pudiéramos extraer de éste lecciones que nos fueran de utilidad para entender lo que hay y para impulsarnos hacia el porvenir ha hecho aguas por todas partes", en Cruz, Adiós historia adiós, p. 241.

71 "La conciencia histórica es la suma de las operaciones mentales por medio de las cueles se construye sentido histórico”, en Rüsen, Tiempo en ruptura, p. 77.
} 
testimonio del pasado desde una separación tajante con el presente del historiador, por tanto, con su misma experiencia. La HTP apunta a una relación temporal que une pasado y presente, fenómeno que permite a fin de cuentas establecer la posibilidad de una función social del historiador, problema que escapa a este trabajo.

Con respecto al segundo problema y ligado a lo anterior, el rol del historiador del tiempo presente en un mundo presentista cobra vital relevancia y nos lleva a una pregunta complicada: ¿no debemos acaso repensar nuestro trabajo como historia magistra vitae? La pregunta es pertinente pero compleja de responder, obliga a una reflexión mayor que escapa estas líneas. Lo que sí estamos en condiciones de afirmar, es que al considerar al historiador del tiempo presente "afectado por el pasado" su función social cobra nuevo matiz. Si la función de la conciencia histórica es caminar hacia la comprensión del sentido del pasado, el rol del historiador del tiempo presente debe, a lo menos, construir sentido histórico para el presente y también para el futuro, yendo en dirección contraria a la aceleración del cambio social, tal como lo ha presentado desde la teoría critica Harmut Rosa ${ }^{72}$, fenómeno indisociable del presentismo en Hartog, Cruz y otros ${ }^{73}$. En este sentido, el historiador del tiempo presente entra en la lógica de un "manifiesto" reciente que llama a salir del cortoplacismo que siempre es para el "ahora" y entrar en discusiones mayores para promover el bienestar social".

El historiador alemán Jörn Rüsen expresa que "el sentido histórico es tiempo interpretado, integrado en la orientación y la motivación de las acciones humanas, y puesto de relieve en la manera y la medida del sufrimiento humano"75. El sentido histórico para Rüsen es la configuración de tres componentes: percepción, interpretación y orientación, categorías que permiten, si son puestas bajo el alero de la operación historiográfica de la HTP, establecer que

\footnotetext{
72 Rosa distingue tres grandes fenómenos de aceleración: tecnológica, del cambio social y de los ritmos de vida. La primera da cuenta de la velocidad dirigida a un objeto, tales como el transporte, la comunicación y la producción. Todos ellos tienden a problematizar el espacio geográfico (los "no lugares" de Marc Augé es uno de los ejemplos que emplea). El cambio social es también acelerado, según Rosa, corresponde a un nivel más estructural de la aceleración que se observa en la producción y reproducción de las instituciones como la familia, el Estado y las organizaciones que dan empleo, entre otras, donde todas ellas tienden al cambio de una manera más rápida, ya que sus lógicas tradicionales tienden a no permanecer (como el puesto de trabajo para toda la vida). Por último, la aceleración de la vida, es explicada por Rosa desde una valoración subjetiva y objetiva de la experiencia. A diferencia de la tecnológica, que se orienta a objetos o servicios (mercancías bajo la antropología de Appadurai), esta mirada asume una mayor cantidad de experiencias por secuencia temporal, lo que lleva a las personas a creer, entre otras cosas, que tienen menos tiempo para realizar sus actividades, ver Rosa, Harmut. 2013. Social Acceleration. A New Theory of Modernity. New York, Columbia University, pp. 71-80.

73 Algunas de estos problemas se han trabajado en otro estudio, ver Ovalle, Daniel. 2020. "Nuestro tiempo contemporáneo: apuntes a Paul Ricoeur, François Hartog, Manuel Cruz y Byung-Chul Han para la Historia del Tiempo Presente", en Ovalle, Alex (editor), Estudios Históricos. Indagación y reflexión en el siglo XXI, La Serena, Universidad de la Serena, pp. 159-173.

74 Guldi, Jo y Armitage, David. 2014. The History Manifesto, U.K, Cambridge University Press, ver http://historymanifesto.cambridge.org/ (Consultado con fecha 11 de octubre de 2019)

${ }^{75}$ Rüsen, Tiempo en ruptura, p. 66.
} 
necesitan del futuro como posibilidad abierta, pues no está exento el sentido histórico de la dimensión funcional que el autor alemán vincula a la interpretación del tiempo para la orientación de la acción, la cual agregamos, no es solamente la acción intelectual del historiador, sino también la del lector. Desde un plano teórico, de la HTP entendida desde su matriz, debe ser complejizada como problema de interpretación del tiempo, lo que ha formado parte del esfuerzo de este trabajo. La historiografía entendida como una práctica social generadora de sentido puede entonces ser vista como una forma de interpretar el tiempo (el tiempo histórico según Ricoeur), donde sus motivaciones y orientaciones parten -para el caso de la HTP- desde acontecimientos generadores de dolor, trauma y conflictos; estos conforman un entramado social de pugnas y luchas por memoria, justicia y verdad, donde la figura del testigo y su palabra posibilita, junto con una batería metodológica, la llamada HTP.

El historiador es parte así de la producción de sentido histórico, con la salvedad que juega un rol generacional. Al poner en práctica la teoría generacional de Karl Mannheim ${ }^{76}$, diremos que el historiador del tiempo presente ocupa una "posición generacional" que implica espacios y formas socio-históricas compartidas con otros sujetos (más allá de las fechas de nacimiento), y es partícipe de una "conexión generacional" en la participación de un proyecto común denominado HTP. Al empujar hacia la historización, ciertos acontecimientos dolorosos -como el caso de las dictaduras latinoamericanas y los vejámenes que llevaron a cabo o la Shoah para el caso europeo- han provocado que el sujeto historiador trabaje por la necesidad de aportar más verdad a la justicia, estableciendo el trabajo memorial como parte de sus posibilidades, tan ciertas como la historia del Renacimiento, el mundo colonial, etc.

Se mencionó más arriba la deuda del historiador del tiempo presente con los testigos, problema de una ética de la historiografía, sobre todo ante el carácter genealógico de la HTP con la llamada "última catástrofe" o la memoria del trauma del cual, hemos dicho, es parte desde la "posición generacional" de su accionar en el mundo con el pasado que estudia. Hay que enfatizar que eso responde, desde el plano teórico, a la relación y tensión entre pasado y presente. La corta distancia temporal que hay entre escritura de la HTP y acontecimiento fundador corresponde a un intervalo vivo de experiencia que transmite y genera sentido histórico gracias a la marca del pasado con el sujeto observador, el historiador.

El sujeto historiador que hace HTP está afectado por ese pasado precisamente porque espera darle una coherencia narrativa y explicativa proyectando en su escritura algún tipo de acción. Si bien la empatía es parte constituyente de su narración histórica -ya que como explica el mismo LaCapra "la empatía es una suerte de vivencia virtual, viaria [...] en la cual la respuesta emocional va acompañada de respeto por el otro y la conciencia de que la vivencia del otro no

\footnotetext{
76 Mannheim, Karl. 1993. “El problema de las generaciones”, Reis № 62, pp. 193-242.
} 
es propia"77- la implicancia emocional del sujeto observador con respecto al pasado no radica en ese otro sin más, sino en ese otro con respecto al observador mismo. Ambos esperan que ese pasado sea generador de acción para el futuro. Esto distingue de manera radical el pasado histórico con el pasado presente, y hace de esta forma de hacer historia un problema para la teoría de la historia que esta investigación intenta problematizar para su comprensión.

Es la vivencia virtual que se comprende desde la empatía por el dolor de otros la que ha permitido que otra generación de sujetos historiadores continúe haciendo historia de la experiencia memorial, no siendo contemporáneos directos con los testigos ni con la experiencia de historiadores más cercanos a los acontecimientos estudiados. Esta cuestión intelectual y teórica no deja de tener relación con los comentarios del problema generacional que rescatamos del trabajo de Mannheim. La comentada "posición generacional" implica la voluntad de compartir visiones del mundo más allá de las fechas de nacimiento. Nos habla de hacer común algo que podría no haber vivido nunca el sujeto en cuestión. Esto es lo que le pasa al historiador del presente que no ha sido contemporáneo de vivencias traumáticas o dolorosas, pero que desde la empatía asume una "conexión generacional" con las víctimas, ya que comparte la necesidad de proyección de acción en la no repetición de hechos como los que se ha vivido.

El fenómeno reciente llamado postmemoria guarda relación con lo que hemos comentado, toda vez que hoy existen sujetos que, estudiando desde la historia del tiempo presente acontecimientos que no le han sido contemporáneos, se sumergen desde una posición generacional y empática en la comprensión de dichos sucesos. La postmemoria, explica Marianne Kirsch, "describe la relación de la generación del después con el trauma personal, colectivo y cultural de la generación anterior, es decir, su relación con las experiencias que recuerdan a través de los relatos, imágenes y comportamientos en medio de los que crecieron"78.

Como se podrá observar el problema central sigue siendo la tensión entre memoria e historia, pero en una perspectiva del sujeto que mira el pasado reciente con vocación de historiador, sin que por esto se pueda desligar tal problemática de los cimientos estructurales, los cuales para esta investigación son de orden temporal: régimen de historicidad proyectado en régimen historiográfico. Bajo la óptica de una perspectiva teorética con respecto a su propia escritura, la HTP se presenta como un fenómeno historiográfico que da cuenta de un problema estructural, a saber, una orientación del tiempo bajo los parámetros del presentismo (asumiendo sus críticas), fenómeno que produce un constante volver sobre el pasado (pasados que no pasan). Pero a la vez obliga a pensar la orientación de esa temporalidad, la que puesta

\footnotetext{
77 LaCapra, Escribir la historia, escribir el trauma, p. 62.

78 Hirsch, Marianne. 2015. La generación de la postmemoria. Escritura y cultura visual después del Holocausto, Madrid, Carpe Noctem, p. 19.
} 
en orden bajo el tipo de relaciones que establece el historiador del tiempo presente epistémica, moral y política- nos muestra la irreductible necesidad de pensar el futuro de su escritura.

\section{A modo de conclusión}

Un libro colectivo de reciente data -dedicado a la teoría de la historia y con ello al problema del tiempo- expresa llamativamente lo siguiente: "Es sintomático que la tesis de François Hartog de que el pensamiento occidental sobre la historia se caracteriza por una sucesión de tres "regímenes de historicidad [...] apenas ha sido probado empíricamente"79. He intentado, lejos de probar científicamente la tesis del presentismo, sumar argumentos a una discusión que apenas germina. Haciéndome cargo de aquello que los editores del libro arriba citado explicitan como una carencia conceptual y empírica con respecto al estudio en las transformaciones de los regímenes del tiempo, he fundamentado que la HTP conviene entenderla como una transformación de la historicidad contemporánea y a la vez posible transgresora de la interpretación del tiempo presentista. Con esto hago eco del llamado de los autores a involucrarnos como historiadores en las llamadas "políticas del tiempo" ${ }^{80}$, posicionando la HTP como parte del entramado de múltiples relaciones sociales de nuestra contemporaneidad.

El presentismo ha sido entendido como sinónimo de una "nueva condición histórica" del mundo globalizado ${ }^{81}$, una serie de experiencias del tiempo donde el presente absorbe el futuro, por tanto, respuesta de un fenómeno que debilitaría una posible función social del historiador, para quien -hijo de su época- las relaciones sociales del tiempo no le son ajenas en su representación del pasado. Se ha esgrimido que la HTP se presenta como una anomalía en un mundo de una débil conciencia histórica y como posibilidad de orientación cultural (generadora de conciencia histórica). La emergencia del testimonio y con ello el problema de múltiples memorias heridas por pasados dolorosos o traumáticos, han hecho de esta forma de escribir la historia una posible herramienta de construcción de sentido histórico, tal como lo hemos entendido desde los aportes de Jörn Rüsen.

Asumido este panorama de "pérdida de evidencia" de la historia como disciplina, la teoría historiográfica permite observar la HTP como producto de los cambios en nuestras visiones del mundo y con ello de nuestra temporalidad. He argumentado la irremediable relación, todavía vigente, entre presentismo, memoria(s) e HTP, en donde existe una ética historiadora desde los testigos (otros tantos muertos) y marcas del pasado, generadas desde distintas experiencias traumáticas en el siglo XX, traumas colectivos e individuos ansiosos de justicia y lucha contra el olvido. Son las memorias en pugna la que reclaman justicia y la historia que, desde su crítica,

\footnotetext{
79 Bevernage y Lorenz, Breaking up Time, p. 9.

80 íbid. p. 12.

${ }^{81}$ Hartog, François. 2016. "Vers une nouvelle condition historique”, Le Débat №118, pp. 169-180.
} 
intenta conciliar -desde el pacto de verdad entre historiador y lector (Ricoeur)- el pasado con el presente, pero sin dejar de mirar al futuro. El historiador no puede ser ajeno al mundo que lo rodea, puede y debe ser fuente de cambio social en vías de un mundo más democrático y menos violento, pero entendiendo que ese cambio no viene de su trabajo, sino de la toma de conciencia de los ciudadanos. No es desde un trabajo normativo donde la HTP se debe presentar, sino desde la comprensión del pasado para su correcta interpretación.

Con todo, la pandemia del Coronavirus que se vive en estos momentos, entendida como un verdadero acontecimiento global (quizás el primero) en curso, está cambiando, sin lugar a dudas, las experiencias temporales de la humanidad y con ello, nos obliga a reevaluar nuestro presentismo contemporáneo. La lucha por las vacunas que ya comienzan a suministrarse en muchos países es un logro de la ciencia y del progreso. ¿Modificará este triunfo de la ciencia nuestros modos de relacionarnos con el tiempo histórico? Eso está por verse, lo cierto es que toda HTP es siempre un conocimiento en constante cambio, no porque cambien las evidencias acerca del pasado reciente, sino porque mientras avanzan los hechos históricos también se modifica la mirada sobre lo reciente. Nada más un ejemplo. A causa de la permanencia de ciertos pasados y siguiendo la tesis descrita de Rousso de la "última catástrofe" como eje articulador de toda HTP, cabe preguntarnos si acaso ¿no será el 18 de octubre nuestra nueva última catástrofe ${ }^{82}$, y con ello, estaríamos asistiendo a la modificación de la conciencia histórica nacional. Por lo menos una conciencia histórico-política. Como hemos dicho, una relación fuerte entre HTP y pasado es de tipo política, lo que trae aparejado el fenómeno ideológico. Hay allí un problema a resolver con respecto a la escritura de la historia del tiempo presente.

Abierta queda también la pregunta planteada por el mismo Hartog: "Me pregunto si el conflicto de las temporalidades podría devenir en un 'lugar común' de preguntas para las ciencias sociales, un punto de encuentro, como lo pudo ser la larga duración, cuando Fernand Braudel llamara, en 1958, a la apertura de una marcha común de las ciencias sociales" ${ }^{83}$. Abierta, pero con más fuerza trasformadora, asumiendo que pensar la historia y los discursos sobre esta, es pensar las relaciones pasado, presente y futuro.

\footnotetext{
82 El 22 de agosto del 2018 el historiador chileno Manuel Gárate (especialista en historia reciente), expresó en una columna de La Tercera: “Nuestra última catástrofe, qué duda cabe, es el Golpe de Estado de 1973", ver El peso de la catástrofe y su contexto: https://www.latercera.com/opinion/noticia/peso-la-catastrofe-contexto/290551/

${ }^{83}$ François Hartog, “Conclusion”, Vingtième Siècle. Revue d'histoire № 117 (2013), 248.
} 


\section{Referencias citadas}

Allier, Eugenia y Crenzel, Emilio (coord.). 2015. The Struggle for Memory in Latin America: Recent History and Political Violence, US, Palgrave Macmillan.

Ankersmit, Frank. 2005. Sublime Historical Experience, Stanford, Stanford University Press.

Aravena, Pablo. 2014. "François Hartog: la historia en un tiempo catastrófico (entrevista)", en Cuadernos de Historia №41, Santiago, pp. 227-234.

Aróstegui, Julio. 2004. La historia vivida. Sobre la historia del tiempo presente, Madrid, Alianza.

Aurell, Jaume. 2005. La escritura de la memoria. De los positivismos a los postmodernismos, Valencia, Universidad de Valencia.

Barash, Jeffrey. 2016. Collective memory and the historical past, Chicago, University of Chicago Press.

Bauman, Zygmunt. 2015. Modernidad líquida, México, Fondo de Cultura Económica.

Bevernage, Berber. y Lorenz, C. 2013. Breaking up Time. Negotiating the Borders between Present, Past and Future, Göttingen, Vandenhoeck \& Ruprecht.

Chakrabarty, Dipesh. 2021. The Climate of History. In a planetary age, Chicago, University of Chicago Press.

Chakrabarty, Dipesh. 2019. "The Planet: An Emergent Humanist Category”, Critical Inquiry N46, Chicago, pp. 1-31.

Cruz, Manuel. 2012. Adiós historia adiós: el abandono del pasado en el mundo actual, Oviedo, Ediciones Nobel.

De Certeau, Michele. 2010. La escritura de la historia, México, Universidad Iberoamericana.

Dosse, François. 2013. Paul Ricoeur. Los sentidos de una vida (1913-2005), Buenos Aires, Fondo de Cultura Económica.

Dosse, François. 2012. El giro reflexivo de la historia. Recorridos epistemológicos y atención a las singularidades, Santiago, Ediciones Universidad Finis Terrae.

Dosse, François. y Goldenstein, Catherine. 2013. Paul Ricoeur: penser la mémoire, París, Seuil.

Escribano, Rodrigo. 2019. "Experience, symbol and communication: a transversal model for the study of historical thought", en Historia Da Historiografia, Vol. 12, № 29, Ouro Preto, pp. 153-178.

Guldi, Jo y Armitage, David. 2014. The History Manifesto, U.K, Cambridge University Press. Disponible en: http://historymanifesto.cambridge.org/. (consultado el 11 de octubre de 2019 ).

Hartog, François. 2003. Régimes d'historcité. Présentisme et experience du témps, París, Seuil.

Hartog, François. 2005. Évidence de l'histoire. Ce que voient les historiens, París, Ed. EHESS.

Hartog, François. 2009. “Historia, memoria y crisis del tiempo ¿Qué papel juega el historiador?”, en Historia y Grafía, Ciudad de México, № 33, pp. 115-131.

Hartog, François. 2010. "Historicité / régime d’historicité", en Delacroix, Christian, Dosse François, García, Patrick y Offenstadt, Nicolas, Historiogrphies II. Concepts et débats, París, Gallimard, pp. 766-771 
Hartog, François. 2013. Croire en l'histoire, París, Flammarion.

Hartog, François. 2013. "The Modern Régime of Historicity in the Face of Two World Wars", en Bevernage, Berber y Lorenz, Chris, Breaking up Time. Negotiating the Borders between Present, Past and Future, Göttingen, Vandenhoeck \& Ruprecht, pp. 124-133.

Hartog, François. 2013. “Conclusion”, en Vingtième Siècle. Revue d’histoire, № 117, París, pp. 247-250.

Hartog, François. 2016. "Vers une nouvelle condition historique”, en Le Débat, №118, París, pp. 169-180.

Hirsch, Marianne. 2015. La generación de la postmemoria. Escritura y cultura visual después del Holocausto, Madrid, Carpe Noctem.

Hobsbawm, Eric. 2003. La era del Imperio 1875-1914, Barcelona, Crítica.

Hölscher, Lucian. 2014. El descubrimiento del futuro, Madrid, Siglo XXI.

Judt, Tony. 2006. Postguerra. Una historia de Europa desde 1945, Barcelona, Taurus.

Juliá, Santos. 2011. Elogio de Historia en tiempos de memoria, Madrid, Marcial Pons.

Kleinberg, Ethan. 2017. Haunting History. For a Deconstructive Approach to the Pas, Stanford, Stanford University Press.

Mannheim, Karl. 1993. “El problema de las generaciones”, en Reis № 62, Madrid, pp.193-242.

LaCapra, Dominick. 2009. Historia y memoria después de Auschwitz, Buenos Aires, Prometeo.

LaCapra, Dominick. 2005. Escribir la historia, escribir el trauma, Buenos Aires, Nueva Visión.

Mudrovcic, María Inés. 2015. “Crisis del futuro: política y tiempo”, en Ariadna histórica. Lenguajes, conceptos, metáforas, №4, Bilbao, pp. 99-115.

Mudrovcic, María Inés. 2013. "Regímenes de historicidad y regímenes historiográficos: del pasado histórico al pasado reciente", en Historiografías № 5, Zaragoza, pp. 11-31.

Nora, Pierre. 2009. Pierre Nora en Les Lieux de mémoire, Santiago, LOM.

Ovalle, Daniel. 2020. “Nuestro tiempo contemporáneo: apuntes a Paul Ricoeur, François Hartog, Manuel Cruz y Byung-Chul Han para la Historia del Tiempo Presente", en Ovalle, Alex (ed.), Estudios Históricos. Indagación y reflexión en el siglo XXI, La Serena, Universidad de la Serena, pp. 159-173.

Ovalle, Daniel. 2019a. "Sujeto histórico y temporalidad en Paul Ricoeur hasta Temps et récit como aportes conceptuales para la teoría de la historia", en Cuadernos de Historia Cultural, № 8, Viña del Mar, pp. 10-33.

Ovalle, Daniel. 2019b. "Actualidad en teoría de la historia: una mirada desde las relaciones con el pasado", en Autoctonía, Vol. 3 №1, Santiago, pp. 16-27.

Ovalle, Daniel. 2019c. "Pensar la conciencia histórica contemporánea. Historicidad y teoría de la historia" en Aravena, Pablo (Ed.), Representación histórica y nueva experiencia del tiempo, Santiago, América en Movimiento, pp. 47-63.

Ovalle, Daniel. 2018. “El historiador del Tiempo Presente: ¿vector de conciencia histórica?” en Moreno, Rodrigo, Corti, Paola, Widow José Luis (eds.), La utilidad de la Historia, Asturias, Trea., pp. 315-328.

Paul, Herman. 2015. Key Issues in Historical Theory, New York, Routledge. 
Paul, Herman. 2015. "Relations to the past: a research agenda for historical theorists", Rethinking History, London, Vol. 19, pp. 450-458.

Peiró, Ignacio. 2004. "La consagración de la memoria: una mirada panorámica a la historiografía contemporánea", en Ayer № 52, España, pp. 179-205.

Pihlainen, Kalle. 2019. La obra de historia. Constructivismo y política del pasado, Santiago, Palinodia.

Pihlainen, Kalle. 2014. “On historical consciousness and popular pasts”, en Historia da Historiografia, № 15, Ouro Petro, pp. 10-26.

Pomian, Krzysztof. 1989. “La crise de l’avenir”, en Le Débat № 7, París, pp. 5-17.

Ricœur, Paul. 2000. La mémoire, I'histoire, I'oubli, París, Seuil.

Ricoeur, Paul. 2000. "L'écriture de l’histoire et la représentation du passé", en Annales, 55, №4, París, pp. 731-747.

Ricoeur, Paul. 1985. Temps et récit III. Le temps raconté, Paris, Seuil.

Rosa, Hartmut. 2013. Social Acceleration. A New Theory of Modernity, New York, Columbia University.

Rousso, Henry. 2018. La última catástrofe. La historia, el presente, lo contemporáneo, Santiago, Editorial Universitaria.

Rousso, Henry. 2015. "Hacia una globalización de la memoria", en Nuevo Mundo Mundos Nuevos, Debates. Puesto en línea el 18 septiembre 2015. Disponible en: http://nuevomundo.revues.org/68429. (Consultado el 14 de diciembre de 2019)

Rousso, Henry. 2007. "La trayectoria de un historiador del tiempo presente", en Pérotin-Dumon, Anne. Historizar el pasado vivo en América Latina. En www.historizarelpasadovivo.cl (consultado el 27 de julio de 2019).

Runia, Eelco. 2006. "Presence”, en History and Theory Vol. 45, Middletown, pp. 1-29.

Schaeffer, J. 2018. "Historia y Hermenéutica", en Oficio. Revista de Historia e Interdisciplina, № 6, Guanajuato, pp. 75-86.

Simon, Zoltán. 2020. The Epochal Event. Transformations in the Entangled Human, Technological and Natural Worlds, U.K, Palgrave Macmillan.

Simon, Zoltán. 2019. History in Times of Unprecedented Change. A Theory for the 21st Century, London, Bloomsbury.

Tamm, Marek. 2014. "Truth, Objectivity and Evidence in History Writing", en Journal of the Philosophy of History Vol. 8, Leiden, pp. 265-290.

Tamm, Marek. y Olivier, Laurent. (eds.). 2019. Rethinking Historical Time: New Approaches to Presentism, London, Bloomsbury.

Traverso, Enzo. 2007. "Historia y memoria. Notas para un debate”, en Franco, María y Levín, Florencia (comp.), Historia reciente. Perspectivas y desafíos para un campo en construcción, Buenos Aires, Paidós, pp. 67-96. 
Veto, Silvana. 2011. "El Holocausto como acontecimiento traumático. Acerca de la incorporación del concepto freudiano de trauma en la historiografía del Holocausto", en Revista de Psicología, № 20, vol. 1, Santiago, pp. 127-151.

Winn, Peter, Stern, Steve, Lorenz, Federico y Marchesi, Aldo. 2014. No hay mañana sin ayer. Batallas por la memoria histórica en el Cono Sur, Santiago, LOM.

Winter, Jay. 2001. "The generation of memory: Reflections on the "Memory boom" in contemporary historical studies", en Canadian Military History, Vol. 10 № 3, Canada, pp. 57-66. 